\title{
Demographics and Clinical and Endoscopic Characteristics of Patients with Helicobacter pylori Infection and Gastroesophageal Reflux Disease: A Case-Control Study
}

\author{
Amir Mari $\mathbb{D}^{1,2}$ Naim Mahroum, ${ }^{3,4}$ Nicola Luigi Bragazzi $\left(\mathbb{D},{ }^{5}\right.$ Mahran Shalaata, ${ }^{2,6}$ \\ Tawfik Khoury $\mathbb{D}^{7},{ }^{7}$ Abdulla Watad, ${ }^{4,8}$ and Mahmud Mahamid $\mathbb{D D}^{1,2}$ \\ ${ }^{1}$ Endoscopy Unit, Nazareth Hospital EMMS, 16100 Nazareth, Israel \\ ${ }^{2}$ Azrieli Faculty of Medicine, Bar-Ilan University, 13195 Safed, Israel \\ ${ }^{3}$ Department of Medicine, Sheba Medical Center, Tel-Hashomer, Israel \\ ${ }^{4}$ Sackler Faculty of Medicine, Tel Aviv University, 52621 Tel Aviv, Israel \\ ${ }^{5}$ School of Public Health, Department of Health Sciences, University of Genoa, 16132 Genoa, Italy \\ ${ }^{6}$ Internal Medicine Department, Nazareth Hospital EMMS, 16100 Nazareth, Israel \\ ${ }^{7}$ Institute of Gastroenterology and Liver Diseases, Naharya Medical Centre, Bar-Ilan University, 13195 Safed, Israel \\ ${ }^{8}$ Department of Medicine 'B', Sheba Medical Center, Tel-Hashomer, Israel \\ Correspondence should be addressed to Amir Mari; amir.mari@hotmail.com
}

Received 22 December 2018; Revised 17 February 2019; Accepted 20 March 2019; Published 6 May 2019

Academic Editor: Tatsuya Toyokawa

Copyright ( 2019 Amir Mari et al. This is an open access article distributed under the Creative Commons Attribution License, which permits unrestricted use, distribution, and reproduction in any medium, provided the original work is properly cited.

\begin{abstract}
Background. The correlation between Helicobacter pylori (H. pylori) and gastroesophageal reflux disease (GERD) is complex. Some studies showed a protective role of $H$. pylori infection against GERD. This study was aimed at assessing the role of $H$. pylori infection in GERD utilizing a large cohort of patients diagnosed with GERD. Methods and Materials. All patients who underwent gastroscopy for an indication of GERD during the study period between 2015 and 2017 at the EMMS Nazareth Hospital were considered eligible for the study and therefore were included. H. pylori infection was determined by the rapid urease test or histology. Severity of esophagitis was assessed using the Los Angeles classification. Univariate analysis was performed to figure out differences between patients according to $H$. pylori infection status. Multivariate regression analysis was conducted to illustrate the predictors of positivity for $H$. pylori infection. Results. 2,508 GERD patients were included with a median age of $49.42 \pm 17.96$ years. H. pylori infection was detected in $299(11.9 \%)$ patients. GERD patients with $H$. pylori infection were found to be younger $(48.83 \pm 17.42$ years versus $44.57 \pm 17.69$ years, $p<0.001)$, have the tendency to smoke more (1406 $(63.6 \%)$ versus $266(89.0 \%)$, $p<0.001)$, and use more proton pump inhibitors or PPIs $(1314(59.5 \%)$ versus $242(80.9 \%), p<0.001)$. In multivariate regression analysis, age (OR 0.987, $p<0.001)$, smoking status (OR 0.190, $p<0.001)$, use of ASA/NSAIDs (OR 1.652, $p=0.004)$, and use of statins (OR 0.499 (95\%CI 0.295-0.846), $p=0.010$ ) were found significant among $H$. pylori-positive individuals. $H$. pylori-positive subjects have less severe esophagitis and more hiatus hernia. Conclusion. Patients with GERD and H. pylori infection were significantly younger, tended to smoke more, and used more PPIs and had significantly lower grades of esophagitis compared to noninfected ones.
\end{abstract}

\section{Introduction}

The association between infectious agents and gastritis has been known for centuries. However, this relation was not strongly implicated until the discovery of Helicobacter pylori (H. pylori) in the early 1980s [1]. Since then, and in addition to gastritis, strong evidences have been accumulated regarding the role of $H$. pylori in multiple gastric disorders including peptic ulcer disease $[2,3]$, gastric cancer, and lymphoma $[4,5]$. H. pylori is spiral-shape slow-growing gram-negative bacteria characterized by urease, catalase, and oxidase positivity [6]. Urease activity is crucial for bacterial survival, as 
well as constituting the basis of $H$. pylori diagnostic testing [7]. In developed countries, the $H$. pylori infection rate is low in childhood; however, it increases with age reaching 10 percent in adulthood and raising up to 50 percent in individuals older than 60 years $[8,9]$. Low socioeconomic status, overcrowding, smoking, family member with $H$. pylori, and unfiltered drinking water were all shown to be directly associated with increased prevalence rates $[10,11]$. The isolation of $H$. pylori from gastric secretions as well as stool culture explains transmissibility among family members [12]. Diagnostic tests of infection are classified as invasive and noninvasive and are based mainly on urease activity. Invasive tests include the urease test, culture, histology, and polymerase chain reaction (PCR) in which gastroscopy is required to obtain stomach tissue $[7,13,14]$. H. pylori infection, if not properly treated, leads to the insurgence of many digestive disorders, such as chronic gastritis, peptic ulcer, upper gastrointestinal bleeding, MALToma, chronic atrophic gastritis, intestinal metaplasia, and distal gastric adenocarcinoma, among others. Triple or quadruple antibiotic-based regimens are the mainstay of therapy. Detailed guidelines for the treatment of $H$. pylori infection were released by the American College of Gastroenterology (ACG) and the Maastricht Group $[15,16]$. H. pylori and GERD are common gastrointestinal conditions in the general population and may coexist. The relationship between $H$. pylori and GERD symptoms and esophagitis is still controversial. Despite the fact that numerous papers showed a protective role of $H$. pylori against GERD and esophagitis [17, 18], one landmark meta-analysis showed inconsistent results [19]. The suggestive protective role has been related to decreased gastric acid secretion due to atrophic gastritis in patients infected with H. pylori [18]. Moreover, reports showed that eradication of $H$. pylori by restoring gastric acid secretion could exacerbate GERD symptoms [20]. Taking these controversies into consideration, we aimed in our study to characterize demographics and endoscopic findings in patients with GERD according to their $H$. pylori infection status.

\section{Material and Methods}

2.1. Ethical Clearance. The current study received ethical approval from the local hospital ethical committee and was conducted according to the 1964 Helsinki declaration and its subsequent amendments. The data was coded in order to preserve the anonymity of the patients. Informed consent was waived because of the noninterventional design of the study.

2.2. Patient Selection. All patients referred to the endoscopy unit at the EMMS Nazareth Hospital (a district universityaffiliated hospital, Nazareth, Israel) for esophagogastroduodenoscopy (EGD) due to GERD symptoms such as heartburn and/or regurgitations or refractory GERD, typical symptoms, or the presence of alarm symptoms between the years 2015 and 2017 were considered potentially eligible and enrolled in the study. Patients were allocated retrospectively, through electronic medical reports at our unit software. All EGD procedures were performed at the single endoscopic unit, at the
TABLE 1: Descriptive statistics of the sample studied.

\begin{tabular}{lc}
\hline Parameter & Value $(n=2,508)$ \\
\hline Ethnicity & $2,100(83.7 \%)$ \\
$\quad$ Arabs & $408(16.3 \%)$ \\
Jews & $29.67 \pm 7.02,29.0$ \\
BMI & \\
Sociodemographic status & $1,524(60.8 \%)$ \\
$\quad$ Rural & $984(39.2 \%)$ \\
Urban & $49.42 \pm 17.96,50.0$ \\
Age & \\
Gender & $1,194(47.6 \%)$ \\
Males & $1,314(52.4 \%)$ \\
Females & $1,672(66.7 \%)$ \\
Smoking status & $96(3.8 \%)$ \\
Alcohol consumption & $259(10.3 \%)$ \\
Comorbidities & $680(27.1 \%)$ \\
ASA/NSAID users & $190(7.6 \%)$ \\
Statin users & $1,556(62.0 \%)$ \\
PPI users &
\end{tabular}

ASA: acetylsalicylic acid; NSAIDs: nonsteroidal anti-inflammatory drugs; PPIs: proton pump inhibitors.

Nazareth Hospital, by five different senior gastroenterologists. Severity of esophagitis was assessed using the Los Angeles classification [21]. H. pylori infection was determined either by histological examination through a biopsy taken during the EGD or by the rapid urease test using commercially available kits in the unit (PyloPlis+ manufactured by Gulf Coast Medical Inc., Oldsmar, FL 34677, USA).

2.3. Statistical Analysis. Before proceeding with any statistical handling and processing, data were visually inspected for potential outliers. The assumption of normal distribution of data was checked conducting the D'Agostino-Pearson omnibus test. Continuous data were expressed as means and standard deviations, whereas categorical parameters were computed as percentages, where appropriate.

Univariate analysis (chi-squared test, Student's $t$-test, and Kruskal-Wallis test) was performed to capture the main differences between subjects seronegative and seropositive for H. pylori.

Multivariate logistic or Poisson's regression analysis was conducted to shed light on the predictors of positivity for $H$. pylori, adjusting for potential confounders.

All statistical analyses were performed with the commercial software "Statistical Package for the Social Sciences" (SPSS version 24.0, IBM, Chicago, IL, USA). A $p$ value of less than 0.05 was considered statistically significant.

\section{Results}

A sample of 2,508 subjects with classical clinical GERD symptoms of heartburn and regurgitations, aged $49.42 \pm$ 17.96 years, was included in the study: most were Arabs (83.7\%), 52.4\% were females, $66.7 \%$ were current smokers, and $10.3 \%$ had comorbidities. Concerning pharmacological 
TABLE 2: Values broken down according to Helicobacter pylori infection status (univariate analysis).

\begin{tabular}{|c|c|c|c|}
\hline Parameter & $\begin{array}{l}\text { Subjects without } H \text {. pylori infection } \\
\qquad(n=2,209)\end{array}$ & $\begin{array}{l}\text { Subjects with H. pylori infection } \\
\qquad(n=299)\end{array}$ & $p$ value \\
\hline Ethnicity & & & 0.157 \\
\hline Arabs $(n=2,100)$ & $\begin{array}{c}1,841(83.3 \% \text { of } H . \text { pylori subjects, } 87.7 \% \\
\text { of Arabs) }\end{array}$ & $\begin{array}{c}259 \text { (86.6\% of } H . \text { pylori subjects, } \\
12.3 \% \text { of Arabs) }\end{array}$ & \\
\hline Jews $(n=408)$ & $\begin{array}{c}368(16.7 \% \text { of } H \text {. pylori subjects, } 90.2 \% \\
\text { of Jews })\end{array}$ & $\begin{array}{c}40(13.4 \% \text { of } H . \text { pylori subjects, } 9.8 \% \\
\text { of Jews) }\end{array}$ & \\
\hline BMI & $29.69 \pm 7.67$ & $29.91 \pm 6.29$ & 0.297 \\
\hline Sociodemographic status & & & 0.256 \\
\hline Rural $(n=1,524)$ & $\begin{array}{c}1,333(60.3 \% \text { of } H . \text { pylori subjects, } 87.5 \% \\
\text { of rural subjects) }\end{array}$ & $\begin{array}{l}191(63.9 \% \text { of } H . \text { pylori subjects, } \\
12.5 \% \text { of rural subjects })\end{array}$ & \\
\hline Urban $(n=984)$ & $\begin{array}{c}876(39.7 \% \text { of } H \text {. pylori subjects, } 89.0 \% \\
\text { of urban subjects) }\end{array}$ & $\begin{array}{c}108(36.1 \% \text { of } H . \text { pylori subjects, } \\
11.0 \% \text { of urban subjects })\end{array}$ & \\
\hline Age & $48.83 \pm 17.42$ & $44.57 \pm 17.69$ & $p \leq 0.001$ \\
\hline Gender & & & 0.902 \\
\hline Males $(n=1,194)$ & $\begin{array}{c}1,053(47.7 \% \text { of } H . \text { pylori subjects, } 88.2 \% \\
\text { of males) }\end{array}$ & $\begin{array}{c}141(47.2 \% \text { of } H . \text { pylori subjects, } \\
11.8 \% \text { of males })\end{array}$ & \\
\hline Females $(n=1,314)$ & $\begin{array}{c}1,156(52.3 \% \text { of } H . \text { pylori subjects, } 88.0 \% \\
\text { of females) }\end{array}$ & $\begin{array}{c}158(52.8 \% \text { of } H . \text { pylori subjects, } \\
12.0 \% \text { of females })\end{array}$ & \\
\hline Smoking status $(n=1,672)$ & $\begin{array}{c}1,406(63.6 \% \text { of } H . \text { pylori subjects, } 84.1 \% \\
\text { of smokers) }\end{array}$ & $\begin{array}{c}266(89.0 \% \text { of } H . \text { pylori subjects, } \\
15.9 \% \text { of smokers })\end{array}$ & $p \leq 0.001$ \\
\hline Alcohol consumption $(n=96)$ & $\begin{array}{c}82(3.7 \% \text { of } H . \text { pylori subjects, } 85.4 \% \text { of } \\
\text { alcohol consumers })\end{array}$ & $\begin{array}{c}14 \text { (4.7\% of } H \text {. pylori subjects, } 14.6 \% \\
\text { of alcohol consumers) }\end{array}$ & 0.421 \\
\hline Comorbidities $(n=259)$ & $\begin{array}{l}222 \text { ( } 10.0 \% \text { of } H . \text { pylori subjects, } 85.7 \% \\
\text { of subjects with comorbidities) }\end{array}$ & $\begin{array}{l}37 \text { (12.4\% of } H \text {. pylori subjects, } 14.3 \% \\
\text { of subjects with comorbidities) }\end{array}$ & 0.224 \\
\hline ASA/NSAID users $(n=680)$ & $\begin{array}{c}613(27.8 \% \text { of } H . \text { pylori subjects, } 90.1 \% \\
\text { of ASA/NSAID users })\end{array}$ & $\begin{array}{c}67 \text { (22.4\% of } H . \text { pylori subjects, } 9.9 \% \\
\text { of ASA/NSAID users) }\end{array}$ & 0.052 \\
\hline Statin users $(n=190)$ & $\begin{array}{c}164(7.4 \% \text { of } H . \text { pylori subjects, } 86.3 \% \text { of } \\
\text { statin users })\end{array}$ & $\begin{array}{c}26(8.7 \% \text { of } H . \text { pylori subjects, } 13.7 \% \\
\text { of statin users })\end{array}$ & 0.416 \\
\hline PPI users $(n=1,556)$ & $\begin{array}{c}1,314 \text { (59.5\% of } H . \text { pylori subjects, } 84.4 \% \\
\text { of PPI users) }\end{array}$ & $\begin{array}{c}242(80.9 \% \text { of } H . \text { pylori subjects, } \\
15.6 \% \text { of PPI users })\end{array}$ & $p \leq 0.001$ \\
\hline
\end{tabular}

ASA: acetylsalicylic acid; BMI: body mass index; NSAIDs: nonsteroidal anti-inflammatory drugs; PPIs: proton pump inhibitors.

TABLe 3: Predictors of Helicobacter pylori infection (multivariate logistic regression analysis).

\begin{tabular}{|c|c|c|c|c|}
\hline \multirow{2}{*}{ Parameter } & \multirow{2}{*}{ OR } & \multicolumn{2}{|c|}{$95 \% \mathrm{CI}$ OR } & \multirow[b]{2}{*}{$p$ value } \\
\hline & & Lower bound & Upper bound & \\
\hline Ethnicity (Arabs versus Jews) & 1.105 & 0.765 & 1.595 & 0.596 \\
\hline BMI & 1.002 & 0.988 & 1.017 & 0.747 \\
\hline Rural versus urban & 1.144 & 0.883 & 1.481 & 0.308 \\
\hline Age & 0.987 & 0.980 & 0.994 & 0.001 \\
\hline Gender & 1.008 & 0.786 & 1.293 & 0.951 \\
\hline Smoking status & 0.190 & 0.112 & 0.324 & 0.001 \\
\hline Alcohol consumption & 0.773 & 0.425 & 1.406 & 0.398 \\
\hline Comorbidities & 0.781 & 0.534 & 1.143 & 0.203 \\
\hline ASA/NSAID users & 1.652 & 1.169 & 2.333 & 0.004 \\
\hline Statin users & 0.499 & 0.295 & 0.846 & 0.010 \\
\hline PPI users & 1.116 & 0.716 & 1.741 & 0.627 \\
\hline Constant & 0.567 & & & 0.301 \\
\hline
\end{tabular}

ASA: acetylsalicylic acid; BMI: body mass index; NSAIDs: nonsteroidal anti-inflammatory drugs; PPIs: proton pump inhibitors. 
TABLE 4

(a) Endoscopic findings of GERD (insurgence and severity of esophagitis) subjects stratified according to the Helicobacter pylori (H. pylori) infection status

\begin{tabular}{|c|c|c|c|c|c|}
\hline \multirow{2}{*}{ H. pylori status $(n=2.508)$} & \multirow{2}{*}{ No esophagitis $(n=1,726)$} & \multicolumn{4}{|c|}{ Esophagitis $(n=782)$} \\
\hline & & Grade A $(n=478)$ & Grade B $(n=245)$ & Grade C $(n=47)$ & Grade D $(n=12)$ \\
\hline H. pylori negative $(n=2,209)$ & $1,559(70.6 \%)$ & $379(17.2 \%)$ & $216(9.8 \%)$ & $43(1.9 \%)$ & $12(0.5 \%)$ \\
\hline H. pylori positive $(n=299)$ & $167(55.9 \%)$ & $99(33.1 \%)$ & $29(9.7 \%)$ & $4(1.3 \%)$ & $0(0.0 \%)$ \\
\hline
\end{tabular}

(b) Outcomes of subjects with GERD symptoms (insurgence of hiatal hernia) stratified according to their Helicobacter pylori infection status

\begin{tabular}{|c|c|c|}
\hline H. pylori status $(n=2,508)$ & No hiatal hernia $(n=1,764)$ & Hiatal hernia $(n=744)$ \\
\hline H. pylori negative $(n=2,209)$ & $\begin{array}{l}1,530(69.3 \% \text { of } H . \text { pylori-negative subjects, } \\
86.7 \% \text { of subjects without hiatal hernia) }\end{array}$ & $\begin{array}{c}679(30.7 \% \text { of } H \text {. pylori-negative subjects, } 91.3 \% \text { of } \\
\text { subjects with hiatal hernia) }\end{array}$ \\
\hline H. pylori positive $(n=299)$ & $\begin{array}{c}234 \text { (78.3\% of } H . \text { pylori-positive subjects, } 13.3 \% \\
\text { of subjects without hiatal hernia) }\end{array}$ & $\begin{array}{c}65 \text { (21.7\% of } H \text {. pylori-positive subjects, } 8.7 \% \text { of } \\
\text { subjects with hiatal hernia) }\end{array}$ \\
\hline
\end{tabular}

TABLE 5: Determinants of insurgence of hiatal hernia in GERD patients (multivariate logistic regression analysis).

\begin{tabular}{|c|c|c|c|c|}
\hline \multirow{2}{*}{ Parameter } & \multirow{2}{*}{ OR } & \multicolumn{2}{|c|}{$95 \% \mathrm{CI}$ OR } & \multirow[b]{2}{*}{$p$ value } \\
\hline & & Lower bound & Upper bound & \\
\hline H. pylori status (negative versus positive) & 1.641 & 1.036 & 2.600 & 0.035 \\
\hline Ethnicity (Arabs versus Jews) & 0.993 & 0.685 & 1.441 & 0.972 \\
\hline BMI & 1.000 & 0.982 & 1.018 & 0.968 \\
\hline Rural versus urban & 0.768 & 0.583 & 1.012 & 0.061 \\
\hline Age & 1.014 & 1.006 & 1.022 & 0.001 \\
\hline Gender & 0.950 & 0.724 & 1.248 & 0.713 \\
\hline Smoking status & 0.916 & 0.539 & 1.555 & 0.745 \\
\hline Alcohol consumption & 0.955 & 0.480 & 1.903 & 0.897 \\
\hline Comorbidities & 0.730 & 0.484 & 1.102 & 0.134 \\
\hline ASA/NSAID users & 0.001 & 0.001 & 0.002 & $p \leq 0.001$ \\
\hline Statin users & 253.885 & 89.148 & 723.041 & $p \leq 0.001$ \\
\hline PPI users & 0.591 & 0.346 & 1.007 & 0.053 \\
\hline Constant & 0.334 & & & 0.074 \\
\hline
\end{tabular}

ASA: acetylsalicylic acid; BMI: body mass index; NSAIDs: nonsteroidal anti-inflammatory drugs; PPIs: proton pump inhibitors.

treatment, $62.0 \%$ consumed PPIs, whereas $7.6 \%$ used statins. H. pylori infection was found positive in 299 patients (11.9\%). For further details, the reader is referred to Table 1.

In the univariate analysis (Table 2), H. pylori-negative and $H$. pylori-positive patients differed for age $(48.83 \pm 17.42$ years versus $44.57 \pm 17.69$ years, $p \leq 0.001$ ), smoking status (1406 (63.6\%) versus $266(89.0 \%), p>0.001)$, and use of PPI (1314 (59.5\%) versus $242(80.9 \%), p \leq 0.001)$, respectively. $70.6 \%$ of the $H$. pylori-non-infected group had no signs of esophagitis in endoscopy. $29.4 \%$ had esophagitis in the following LA classification severity order (17.2\% had esophagitis LA A, 9.8\% had esophagitis LA B, and $1.9 \%$ and $0.5 \%$ had LA D). In turn, $54.1 \%$ of the $H$. pylori-infected group had signs of esophagitis in endoscopy, in the following LA classification severity order (33.1\% had esophagitis LA A, 9.7\% had esophagitis LA B, $1.9 \%$ and $1.3 \%$ had LA C, and $0 \%$ had LA D). $H$. pylori-infected patients had less hiatus hernias (21.7\%), compared to noninfected patients (30.7\%).

In the multivariate logistic regression analysis (Table 3 ), age (OR 0.987 (95\%CI 0.980-0.994), $p<0.001$ ), smoking status (OR 0.190 (95\%CI 0.112-0.324), $p<0.001$ ), use of aspirin/nonsteroidal anti-inflammatory drugs (ASA/NSAIDs) (OR 1.652 (95\%CI 1.169-2.333), $p=0.004)$, and use of statins (OR 0.499 (95\%CI 0.295-0.846), $p=0.010$ ) were assessed.

Concerning the outcomes, $H$. pylori-infected and noninfected subjects differed in terms of insurgence $(p<0.001)$ and severity $(p=0.003)$ of esophagitis (Table $4(a))$ and insurgence of hiatal hernia $(p=0.001$, Table $4(b))$. No differences could be found in terms of prevalence of Barrett's esophagus.

Confirming the univariate analysis, the multivariate logistic regression shows that with respect to $H$. pylori-positive GERD patients, $H$. pylori-negative GERD individuals have a 
TABLE 6: Determinants of insurgence of esophagitis in GERD patients (multivariate logistic regression analysis).

\begin{tabular}{|c|c|c|c|c|}
\hline \multirow{2}{*}{ Parameter } & \multirow{2}{*}{ OR } & \multicolumn{2}{|c|}{$95 \%$ CI OR } & \multirow[b]{2}{*}{$p$ value } \\
\hline & & Lower bound & Upper bound & \\
\hline H. pylori status (negative versus positive) & 0.611 & 0.474 & 0.787 & $p \leq 0.001$ \\
\hline Ethnicity (Arabs versus Jews) & 0.786 & 0.622 & 0.995 & 0.045 \\
\hline BMI & 0.995 & 0.982 & 1.007 & 0.395 \\
\hline Rural versus urban & 0.957 & 0.801 & 1.143 & 0.629 \\
\hline Age & 0.997 & 0.992 & 1.002 & 0.242 \\
\hline Gender & 1.199 & 1.007 & 1.426 & 0.041 \\
\hline Smoking status & 0.370 & 0.265 & 0.519 & $p \leq 0.001$ \\
\hline Alcohol consumption & 0.859 & 0.551 & 1.339 & 0.503 \\
\hline Comorbidities & 0.768 & 0.584 & 1.011 & 0.060 \\
\hline ASA/NSAID users & 0.779 & 0.629 & 0.965 & 0.022 \\
\hline Statin users & 1.209 & 0.831 & 1.761 & 0.321 \\
\hline PPI users & 1.359 & 0.990 & 1.866 & 0.058 \\
\hline Constant & 1.913 & & & 0.120 \\
\hline
\end{tabular}

ASA: acetylsalicylic acid; BMI: body mass index; NSAIDs: nonsteroidal anti-inflammatory drugs; PPIs: proton pump inhibitors.

crude odds ratio (OR) of $1.598(95 \% \mathrm{CI} 1.196-2.134, p=0.002)$ and a crude OR of $1.641(95 \%$ CI $1.036-2.600, p=0.035)$ of developing hiatal hernia (Table 5). Conversely, they had a crude OR of 0.527 (95\%CI $0.412-0.675, p<0.001)$ and an adjusted OR of 0.611 (95\%CI 0.474-0.787, $p<0.001$ ) of developing esophagitis (Table 6). Positivity for $H$. pylori impacted also on the severity of esophagitis $(p=0.047$, Table 7).

\section{Discussion}

During the last decade, there has been a decrease in the prevalence of $H$. pylori infection; the prevalence of GERD, Barrett's esophagus, and esophageal adenocarcinoma has increased [22]. In our study, the prevalence of $H$. pylori infection among patients with symptoms suggestive of GERD was approximately $12 \%$, which goes in parallel with the assumed inverse correlation between these two conditions. Chung et al. [23] showed in a Korean cohort of matched age and sex individuals lower prevalence of $H$. pylori infection in patients with GERD compared to controls. Furthermore, the authors reported that this association is negatively maintained throughout advanced grades of esophagitis, therefore suggesting a protective role of $H$. pylori against GERD. Indeed, our study found similar findings showing that advanced stages of esophagitis are less prevalent in patients with GERD and with $H$. pylori infection.

Epidemiological studies worldwide showed $H$. pylori infection to be acquired earlier in life in developing countries in opposite to developed countries where infection peaks after the age of 60 [24]. The median age of patients with GERD enrolled in our study differed among $H$. pyloriinfected and noninfected individuals. H. pylori-infected patients were much younger than noninfected persons indicating an earlier acquisition of infection. Our findings suggest closer pictures to developing world. In terms of ethnicity, in contrast to the findings of Everhart et al. [25] that Blacks and Hispanics were found to have a higher prevalence of $H$. pylori infection, we found no difference in both groups analyzed. The authors concluded this ethnic variation to be probably explained by differences in socioeconomic status.

Relationship between smoking status and $H$. pylori infection has given contrasting findings in the literature [26]. Ogihara and collaborators found that current smokers had a 0.82 - (95\%CI 0.74-0.91) fold greater risk of H. pylori infection than those who had never smoked, with current cigarette consumption exhibiting a dose-dependently negative association with H. pylori [27]. This association was strong in younger subjects. Authors postulated that smoking-induced increased gastric acidity could play a major role in leading to $H$. pylori infection. Furthermore, polymorphisms could explain the relationship between smoking status and $H$. pylori [28]. On the other hand, Zhang and coauthors failed to find a statistically significant relationship between smoking status and H. pylori infection. Our data showed significantly higher smoking rates among $H$. pylori-positive individuals compared to negative persons [29].

In our study, alcohol drinking was not associated with $H$. pylori infection. In other studies, such as that by Ogihara and coworkers, current drinkers had a 0.88 - (95\%CI 0.79-0.98) fold greater risk of $H$. pylori infection than those who had never consumed alcohol [28].

Giral et al. [23] showed that PPI use in patients infected with $H$. pylori was associated with greater inhibition of gastric acid secretion when compared to uninfected individuals. Similar findings were demonstrated by Verdu et al.; by this manner, our data showed that $H$. pylori-infected patients have significantly greater proportion of PPI use. These findings have two main implications. First, while PPI is a guideline-recommended part of therapy, when it is used on top of $H$. pylori infection, it leads to substantially higher degrees of acid secretion inhibition. Second, while inhibition of gastric acid secretion seems to explain the protective role 
TABLE 7: Determinants of severity of esophagitis in GERD patients (Poisson's regression analysis).

\begin{tabular}{|c|c|c|c|c|}
\hline Parameter & $B$ & SE & Wald's chi-square & Sig. \\
\hline Constant & 0.027 & 0.2868 & 0.009 & 0.925 \\
\hline Ethnicity (Arabs versus Jews) & 0.082 & 0.0799 & 1.062 & 0.303 \\
\hline Rural versus urban & -0.012 & 0.0607 & 0.039 & 0.843 \\
\hline Gender & 0.002 & 0.0596 & 0.001 & 0.971 \\
\hline Smoking status & 0.036 & 0.1146 & 0.096 & 0.756 \\
\hline Alcohol consumption & 0.018 & 0.1494 & 0.015 & 0.902 \\
\hline Comorbidities & 0.041 & 0.0919 & 0.202 & 0.653 \\
\hline ASA/NSAID users & -0.018 & 0.0710 & 0.067 & 0.796 \\
\hline Statin users & 0.028 & 0.1285 & 0.046 & 0.830 \\
\hline PPI users & -0.086 & 0.1038 & 0.693 & 0.405 \\
\hline H. pylori status (negative versus positive) & 0.168 & 0.0847 & 3.956 & 0.047 \\
\hline BMI & 0.001 & 0.0048 & 0.001 & 0.996 \\
\hline Age & 0.002 & 0.0017 & 1.779 & 0.182 \\
\hline
\end{tabular}

ASA: acetylsalicylic acid; BMI: body mass index; NSAIDs: nonsteroidal anti-inflammatory drugs; PPIs: proton pump inhibitors.

of $H$. pylori infection against GERD and higher degrees of esophagitis, this explains the lower prevalence rate of advanced grades of esophagitis in $H$. pylori-infected individuals. As shown in this, we saw our findings as going consistent with previous studies in medical literature.

While infection of $H$. pylori is assumed to be protective against GERD, the presence of hiatal hernia after eradication of $H$. pylori contributes to the development of GERD [30]. In our study, most of the patients enrolled had no hiatal hernia. Taking into consideration the presence of symptoms of GERD in all patients enrolled, hiatal hernia was more common in $H$. pylori-negative patients. This sheds light on the pathogenetic correlation between GERD and $H$. pylori in the presence of hiatal hernia.

Our study, when compared to similar studies in the literature, has several strong points: a large cohort of patients with well-defined characteristics, as well as a quite uniform ethnic homogeneity, as this prevents possible bias. Another point is that patients were screened endoscopically due to GERD symptoms including not only those with esophagitis but also those who were previously diagnosed with GERD as this permitted a larger cohort to be included.

The retrospective manner of the study and operatordependent endoscopy and the clinical diagnosis of GERD without having $\mathrm{PH}$ monitoring to confirm acid reflux are all part of our limitations.

In conclusion, patients with GERD who tested positive for $H$. pylori were younger, tend to smoke more, and use more PPI than those who tested negative. In addition, patients infected with $H$. pylori had more esophagitis; however, they had less severe esophagitis compared to noninfected patients.

\section{Data Availability}

The data used to support the findings of this study are available from the corresponding author upon request. Data was collected retrospectively by authorized researchers.

\section{Ethical Approval}

Our institutional ethics committee approved this study.

\section{Conflicts of Interest}

The authors declare that they have no conflicts of interest.

\section{References}

[1] B. J. Marshall and J. R. Warren, "Unidentified curved bacilli in the stomach of patients with gastritis and peptic ulceration," The Lancet, vol. 1, no. 8390, pp. 1311-1315, 1984.

[2] G. N. Tytgat and E. A. Rauws, "Campylobacter pylori and its role in peptic ulcer disease," Gastroenterology clinics of North America, vol. 19, no. 1, pp. 183-196, 1990.

[3] A. Lanas and F. K. L. Chan, "Peptic ulcer disease," The Lancet, vol. 390, no. 10094, pp. 613-624, 2017.

[4] F. Wang, W. Meng, B. Wang, and L. Qiao, "Helicobacter pylori-induced gastric inflammation and gastric cancer," Cancer Letters, vol. 345, no. 2, pp. 196-202, 2014.

[5] M. I. Pereira and J. A. Medeiros, "Role of Helicobacter pylori in gastric mucosa-associated lymphoid tissue lymphomas," World Journal of Gastroenterology, vol. 20, no. 3, pp. 684698, 2014.

[6] C. S. Goodwin and B. W. Worsley, "Microbiology of Helicobacter pylori," Gastroduodenal Disease and Helicobacter pylori, vol. 22, no. 1, pp. 5-19, 1993.

[7] K. Nishikawa, T. Sugiyama, M. Kato et al., "A prospective evaluation of new rapid urease tests before and after eradication treatment of Helicobacter pylori, in comparison with histology, culture and ${ }^{13} \mathrm{C}$-urea breath test," Gastrointestinal Endoscopy, vol. 51, no. 2, pp. 164-168, 2000.

[8] R. E. Pounder and D. Ng, "The prevalence of Helicobacter pylori infection in different countries," Alimentary pharmacology \& therapeutics, vol. 9, Supplement 2, pp. 33-39, 1995.

[9] J. E. Everhart, "Recent developments in the epidemiology of Helicobacter pylori," Gastroenterology Clinics of North America, vol. 29, no. 3, pp. 559-578, 2000. 
[10] J. Torres, Y. Leal-Herrera, G. Perez-Perez et al., “A communitybased seroepidemiologic study of Helicobacter pylori infection in Mexico," The Journal of Infectious Diseases, vol. 178, no. 4, pp. 1089-1094, 1998.

[11] R. S. Mhaskar, I. Ricardo, A. Azliyati et al., "Assessment of risk factors of helicobacter pylori infection and peptic ulcer disease," Journal of Global Infectious Diseases, vol. 5, no. 2, pp. 60-67, 2013.

[12] J. Parsonnet, H. Shmuely, and T. Haggerty, "Fecal and oral shedding of Helicobacter pylori from healthy infected adults," JAMA, vol. 282, no. 23, pp. 2240-2245, 1999.

[13] S. J. Czinn, "Helicobacter pylori infection: detection, investigation, and management," The Journal of Pediatrics, vol. 146, no. 3, pp. S21-S26, 2005.

[14] J. Guarner, N. Kalach, Y. Elitsur, and S. Koletzko, "Helicobacter pylori diagnostic tests in children: review of the literature from 1999 to 2009," European Journal of Pediatrics, vol. 169, no. 1, pp. 15-25, 2010.

[15] W. D. Chey, G. I. Leontiadis, C. W. Howden, and S. F. Moss, "ACG clinical guideline: treatment of Helicobacter pylori infection," American Journal of Gastroenterology, vol. 112, no. 2, pp. 212-239, 2017.

[16] P. Malfertheiner, F. Megraud, C. A. O'Morain et al., "Management of Helicobacter pylori infection-the Maastricht V/Florence Consensus Report," Gut, vol. 66, no. 1, pp. 630, 2017.

[17] S. J. Chung, S. H. Lim, J. Choi et al., "Helicobacter pylori serology inversely correlated with the risk and severity of reflux esophagitis in Helicobacter pylori endemic area: a matched case-control study of 5,616 health check-up Koreans," Journal of Neurogastroenterology and Motility, vol. 17, no. 3, pp. 267273, 2011.

[18] T. Shirota, M. Kusano, O. Kawamura, T. Horikoshi, M. Mori, and T. Sekiguchi, "Helicobacter pylori infection correlates with severity of reflux esophagitis: with manometry findings," Journal of Gastroenterology, vol. 34, no. 5, pp. 553-559, 1999.

[19] A. Raghunath, A. P. Hungin, D. Wooff, and S. Childs, "Prevalence of Helicobacter pylori in patients with gastro-oesophageal reflux disease: systematic review," BMJ, vol. 326, no. 7392, p. 737, 2003

[20] M. Feldman, B. Cryer, D. Sammer, E. Lee, and S. J. Spechler, "Influence of $H$. pylori infection on meal-stimulated gastric acid secretion and gastroesophageal acid reflux," American Journal of Physiology-Gastrointestinal and Liver Physiology, vol. 277, no. 6, pp. G1159-G1164, 1999.

[21] L. R. Lundell, J. Dent, J. R. Bennett et al., "Endoscopic assessment of oesophagitis: clinical and functional correlates and further validation of the Los Angeles classification," Gut, vol. 45, no. 2, pp. 172-180, 1999.

[22] H. B. el-Serag and A. Sonnenberg, "Opposing time trends of peptic ulcer and reflux disease," Gut, vol. 43, no. 3, pp. 327333, 1998.

[23] A. Giral, C. A. Celikel, O. Ozdogan, N. Tozun, N. B. Ulusoy, and C. Kalayci, "Impact of Helicobacter pylori eradication on the anti-secretory efficacy of lansoprazole in gastroesophageal reflux disease patients," Journal of Gastroenterology and Hepatology, vol. 20, no. 12, pp. 1886-1891, 2005.

[24] B. L. Smoak, P. W. Kelley, and D. N. Taylor, "Seroprevalence of Helicobacter pylori infections in a cohort of US Army recruits," American Journal of Epidemiology, vol. 139, no. 5, pp. 513519, 1994.
[25] J. E. Everhart, D. Kruszon-Moran, G. I. Perez-Perez, T. S. Tralka, and G. McQuillan, "Seroprevalence and ethnic differences in Helicobacter pylori infection among adults in the United States," The Journal of Infectious Diseases, vol. 181, no. 4, pp. 1359-1363, 2000.

[26] G. Parasher and G. L. Eastwood, "Smoking and peptic ulcer in the Helicobacter pylori era," European Journal of Gastroenterology \& Hepatology, vol. 12, no. 8, pp. 843-853, 2000.

[27] A. Ogihara, S. Kikuchi, A. Hasegawa et al., "Relationship between Helicobacter pylori infection and smoking and drinking habits," Journal of Gastroenterology and Hepatology, vol. 15 , no. 3, pp. 271-276, 2000.

[28] N. Hamajima, H. Ito, K. Matsuo, K. Tajima, and S. Tominaga, "Helicobacter pylori seropositivity, the interleukin 1B polymorphism, and smoking among first-visit outpatients," Asian Pacific Journal of Cancer Prevention, vol. 3, no. 1, pp. 23-28, 2002.

[29] L. Zhang, W. J. Blot, W. C. You et al., "Helicobacter pylori antibodies in relation to precancerous gastric lesions in a high-risk Chinese population," Cancer Epidemiology and Prevention Biomarkers, vol. 5, no. 8, pp. 627-630, 1996.

[30] H. Hamada, K. Haruma, M. Mihara et al., "High incidence of reflux oesophagitis after eradication therapy for Helicobacter pylori: impacts of hiatal hernia and corpus gastritis," Alimentary Pharmacology and Therapeutics, vol. 14, no. 6, pp. 729735,2000 . 


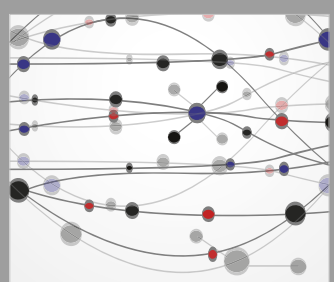

The Scientific World Journal
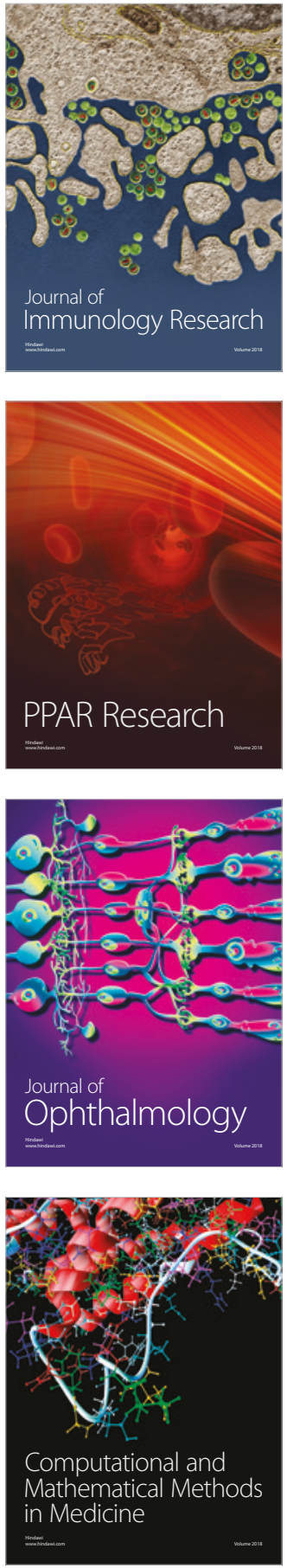

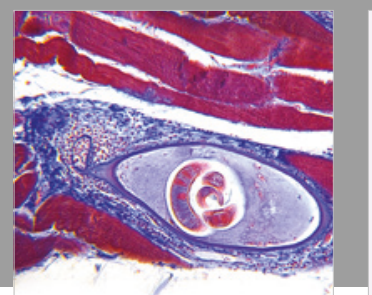

Gastroenterology Research and Practice

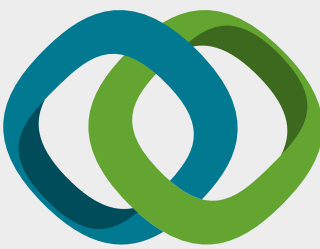

\section{Hindawi}

Submit your manuscripts at

www.hindawi.com
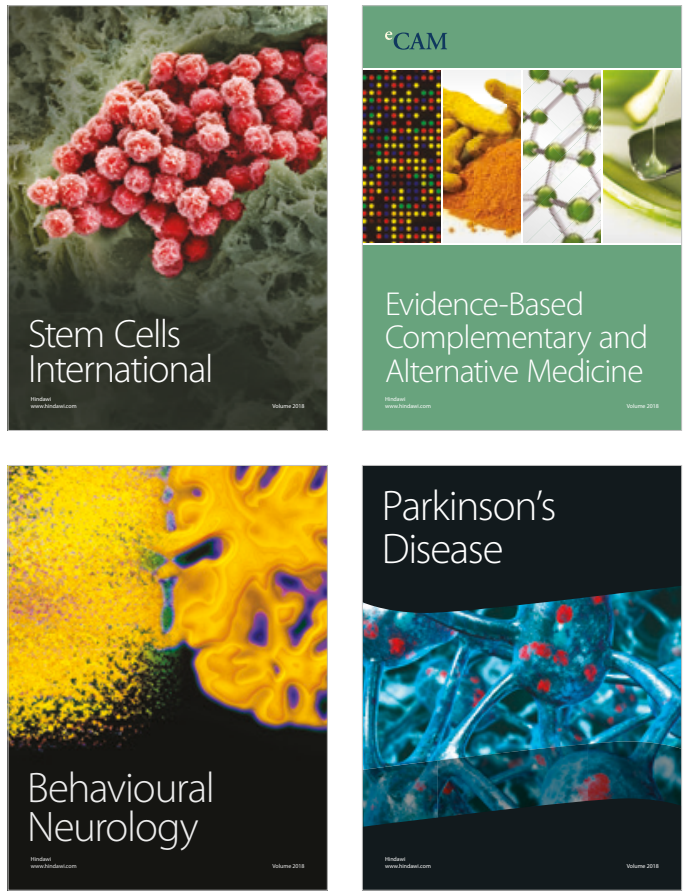

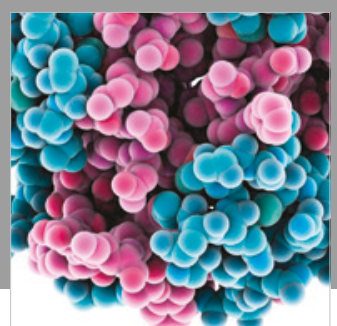

ournal of

Diabetes Research

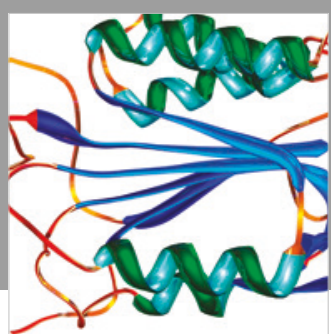

Disease Markers
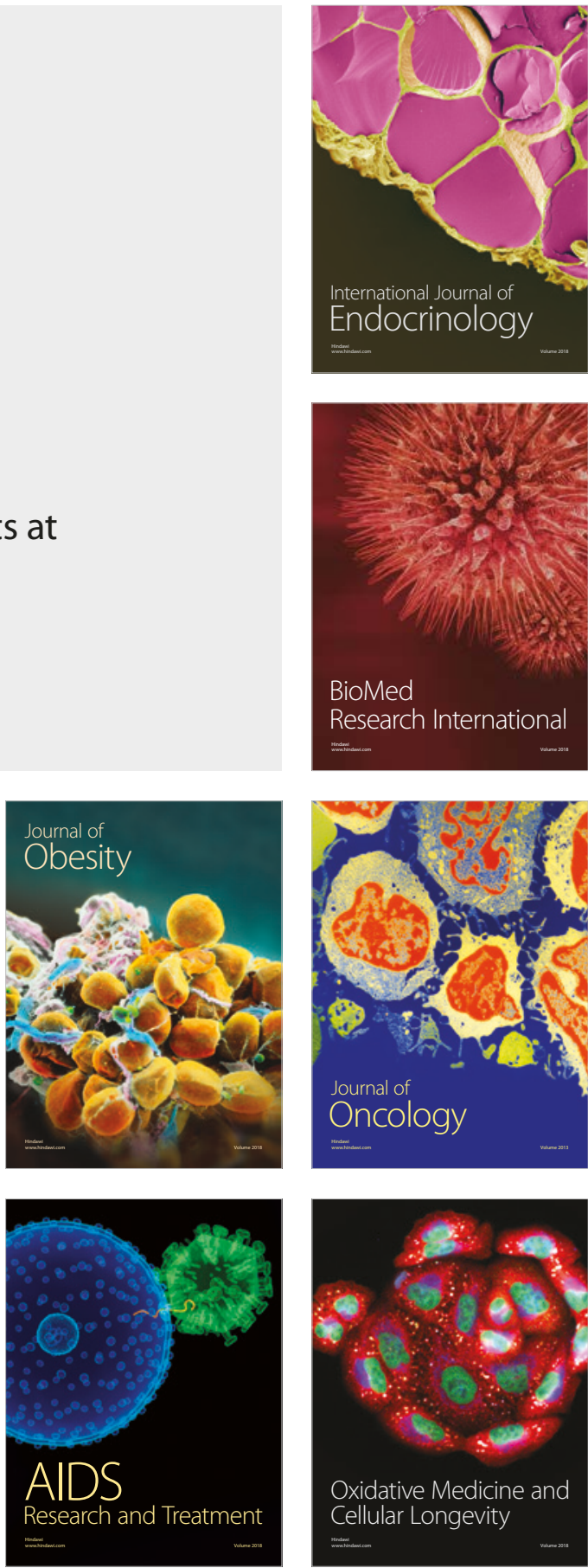